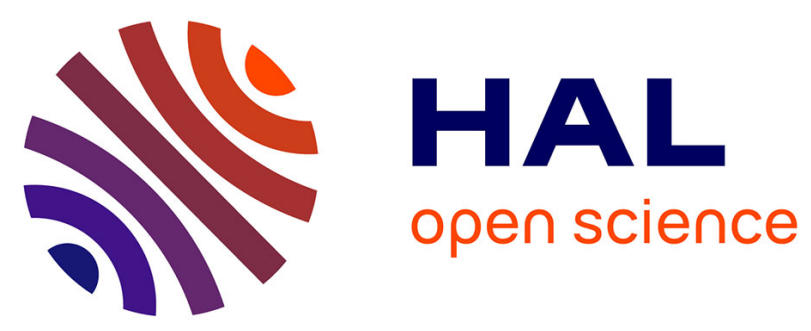

\title{
Epitaxial NiWO4 films on Ni(110): Experimental and theoretical study of surface stability
}

N. Doudin, S. Pomp, M. Blatnik, R. Resel, M. Vorokhta, Jacek Goniakowski, Claudine Noguera, F.P. Netzer, S. Surnev

\section{- To cite this version:}

N. Doudin, S. Pomp, M. Blatnik, R. Resel, M. Vorokhta, et al.. Epitaxial NiWO4 films on Ni(110): Experimental and theoretical study of surface stability. Surface Science: A Journal Devoted to the Physics and Chemistry of Interfaces, 2017, 659, pp.20-30. 10.1016/j.susc.2017.02.003 . hal-01469391

\section{HAL Id: hal-01469391 https://hal.sorbonne-universite.fr/hal-01469391}

Submitted on 16 Feb 2017

HAL is a multi-disciplinary open access archive for the deposit and dissemination of scientific research documents, whether they are published or not. The documents may come from teaching and research institutions in France or abroad, or from public or private research centers.
L'archive ouverte pluridisciplinaire HAL, est destinée au dépôt et à la diffusion de documents scientifiques de niveau recherche, publiés ou non, émanant des établissements d'enseignement et de recherche français ou étrangers, des laboratoires publics ou privés. 


\section{Epitaxial $\mathrm{NiWO}_{4}$ films on $\mathrm{Ni}(110)$ : experimental and theoretical study of surface stability}

N. Doudin ${ }^{1}$, S. Pomp ${ }^{1}$, M. Blatnik ${ }^{1}$, R. Resel ${ }^{2}$, M. Vorokhta ${ }^{3}$, J. Goniakowski $^{4,5^{*}}$,

C. Noguera ${ }^{4,5}$, F.P. Netzer ${ }^{1}$, and S. Surnev ${ }^{1 *}$

${ }^{1}$ Surface and Interface Physics, Institute of Physics, Karl-Franzens University Graz, Universitätsplatz 5, 8010 Graz, Austria

${ }^{2}$ Institute of Solid State Physics, Graz University of Technology, Petersgasse 16, 8010 Graz, Austria

${ }^{3}$ Charles University in Prague, Faculty of Mathematics and Physics, V Holešovičkách 2, Prague 18000, Czech Republic

${ }^{4}$ CNRS, Institut des Nanosciences de Paris, UMR 7588, 4 place Jussieu, 75005 Paris, France

${ }^{5}$ Sorbonne Universités, UPMC Univ Paris 06, Institut des NanoSciences de Paris, F-75005, Paris, France

Keywords : Nickel tungstate, polar surfaces, faceting, scanning tunneling microscopy, X-ray photoelectron spectroscopy, X-ray diffraction, density functional theory

${ }^{*}$ Corresponding authors:

svetlozar.surnev@uni-graz.at

jacek.goniakowski@insp.jussieu.fr 


\begin{abstract}
Despite the application potential of nickel tungstate $\left(\mathrm{NiWO}_{4}\right)$ in heterogeneous catalysis, humidity and gas sensing, etc, its surfaces have essentially remained unexplored. In this work, $\mathrm{NiWO}_{4}$ nanoparticles and films with the wolframite structure have been grown via a solidstate reaction of $\left(\mathrm{WO}_{3}\right)_{3}$ clusters and a $\mathrm{NiO}(100)$ film on a $\mathrm{Ni}(110)$ crystal surface and characterized by a variety of experimental techniques, including $\mathrm{x}$-ray photoelectron spectroscopy (XPS), scanning tunneling microscopy (STM) and x-ray diffraction (XRD), combined with ab-initio density functional theory (DFT) calculations. $\mathrm{NiWO}_{4}$ grows initially as three-dimensional (3D) crystalline nanoparticles displaying mainly two crystalline facets vicinal to the $(100)$ surface, which merge with increasing the $\left(\mathrm{WO}_{3}\right)_{3}$ coverage into a quasicontinuous epitaxial film. The DFT results provide an account of the energetics of $\mathrm{NiWO}_{4}$ low index surfaces and highlight the role of faceting in the stabilization of extended polar (100) terraces. These combined experimental and theoretical results show that interaction with a metal substrate and vertical confinement may stabilize oxide nano-objects with high energy facets, able to enhance their reactivity.
\end{abstract}




\section{INTRODUCTION}

The first row transition metal tungstates $\mathrm{MWO}_{4}(\mathrm{M}=\mathrm{Mn}, \mathrm{Fe}, \mathrm{Co}, \mathrm{Ni})$ belong to a technologically important family of materials, which crystallize with the monoclinic wolframite structure, space group P2/c. Among them, nickel tungstate $\left(\mathrm{NiWO}_{4}\right)$ has a great application potential in the heterogeneous catalysis, ${ }^{1-7}$ humidity and gas sensors, ${ }^{8-10}$ microwave devices, ${ }^{11}$ and photoanodes. ${ }^{12,13}$ Also, $\mathrm{NiWO}_{4}$ has been demonstrated recently to exhibit electrochromic properties, ${ }^{14-16}$ which are superior to those of its binary $\mathrm{NiO}$ and $\mathrm{WO}_{3}$ constituents. With the advance of nanotechnologies there is a growing interest in preparing $\mathrm{NiWO}_{4}$ structures at the nanoscale, where surfaces and interfaces are playing a key role in determining novel physical and chemical properties of these materials. Whereas the bulk crystal structure of $\mathrm{NiWO}_{4}$ has been well established by x-ray ${ }^{17}$ and neutron ${ }^{18}$ diffraction, the $\mathrm{NiWO}_{4}$ surfaces are essentially unexplored. This is due to the fact that nickel tungstate compounds have been mostly synthesized in a polycrystalline form, while only few studies report on the growth of well-shaped $\mathrm{NiWO}_{4}$ single crystals. ${ }^{19}$ Fundamental studies of wolframite surfaces are scarce, in general, and even more so when polar orientations are considered. Growing epitaxial oxide thin films on single crystal metal supports allows one to prepare well-defined surfaces, which can be investigated with atomic precision using modern surface analytic tools. ${ }^{20}$

Recently, we have fabricated two-dimensional (2-D) $\mathrm{Cu}^{21}$ - and $\mathrm{Fe}^{22}$ - tungstate nanolayers on $\mathrm{Cu}(110)$ and $\mathrm{Pt}(111)$ surfaces, respectively, via an ultrahigh vacuum (UHV) surface epitaxial growth route using an on-surface solid-state chemical reaction in two dimensions. This preparation approach differs drastically from the conventional methods for bulk $\mathrm{NiWO}_{4}$ production, where typically chemical reaction of molten powders, mechanical grinding in a vibrating mill, or high-temperature decomposition of complex precursors are used.

Here, instead, the reacting components are brought together in the form of structurally welldefined oxide phases, a $\mathrm{NiO}(100)$ film and $\left(\mathrm{WO}_{3}\right)_{3}$ clusters, on a single crystal $\mathrm{Ni}(110)$ support; their reaction to form an epitaxial stoichiometric $\mathrm{NiWO}_{4}(100)$ film has been initiated by oxidative annealing at elevated temperature and has been investigated in situ by a combination of x-ray photoelectron spectroscopy (XPS) with synchrotron radiation and scanning tunneling microscopy (STM) with atomic resolution, and ex situ by x-ray diffraction (XRD). In contrast to any previous work on $\mathrm{NiWO}_{4}$ films, this study is the first one showing the growth of well-ordered epitaxial $\mathrm{NiWO}_{4}$ films, whose surface structure was characterized at the atomic level. The stability of various low index surfaces of $\mathrm{NiWO}_{4}$ has been explored 
via DFT+U calculations, with a specific focus on the observed polar (100) orientation. We conclude that the observed morphology of the $\mathrm{NiWO}_{4}$ film is likely driven by the interaction with the Ni substrate and by the vertical confinement in the ultrathin oxide film. Two structural phases are highlighted which show that the $\mathrm{NiWO}_{4}(100)$ surface is faceted into two vicinal surfaces, (1611) and (811), with low energy (211) ledges. Models of edge and terrace configurations are proposed.

\section{METHODS}

The STM experiments were performed in an UHV system (base pressure $\sim 1 \times 10^{-10}$ mbar) containing a VT-STM/AFM (Omicron), a LEED optics and a cylindrical mirror analyzer (CMA) for Auger electron spectroscopy (AES), as well as the usual facilities for sample manipulation, surface cleaning and thin film evaporation. ${ }^{23}$ STM images were recorded at room temperature in constant current mode with electrochemically etched $\mathrm{W}$ tips; the bias values cited are referred with respect to the sample.

High-resolution x-ray photoelectron spectroscopy (XPS) experiments were conducted at the Materials Science beamline, at the Elettra synchrotron light source in Trieste, Italy. The UHV chamber was equipped with a spherical electron energy analyzer (mean radius of $150 \mathrm{~mm}$ ), rear view LEED optics and facilities for sample cleaning and thin film deposition. The photoemission spectra were taken at photon energies of $120 \mathrm{eV}, 130 \mathrm{eV}, 640 \mathrm{eV}$ and $950 \mathrm{eV}$ for the valence band and the $\mathrm{W} 4 \mathrm{f}, \mathrm{O} 1 \mathrm{~s}$ and $\mathrm{Ni} 2 \mathrm{p}$ core levels, respectively, with a total energy resolution of $\sim 200 \mathrm{meV}$. The binding energy scale was calibrated with respect to the Fermi energy of the metal substrate, and all spectra were normalized to the secondary electron background at a few eV lower binding energy than the respective core level peak. A Shirley background was subtracted from the core level spectra prior to the peak decomposition analysis. The latter has been performed with the help of free-ware least-squares minimization software, FitXPS. ${ }^{24}$ The core-level spectra have been decomposed into several components, whose individual shape consists of a Donjach-Šunjić profile convoluted with a Gaussian distribution. ${ }^{25}$

X-ray diffraction measurements were performed at atmospheric conditions with a Philips X'Pert diffractometer equipped with an ATC3 texture cradle using chromium radiation from a sealed tube. At the secondary side a flat graphite single crystal was used to select monochromatic $\mathrm{K}_{\alpha}$ radiation $(\lambda=2.291 \AA$ ), but the monochromator was transmissive also for 
the wavelengths $\lambda / 2, \lambda / 3, \ldots$. The experimental data are presented in terms of scattering vector $q$ instead of scattering angles $2 \theta$ obtained by the following transformation: $q=(4 \pi / \lambda)$ $\sin \theta$. Specular scans were performed to detect the orientation of the single crystalline substrate, of the $\mathrm{NiO}$ and $\mathrm{NiWO}_{4}$ crystallites relative to the substrate surface. The results are evaluated by comparing the experimentally observed peak positions with peak positions calculated by using the single crystal structure of the materials. An fcc structure of nickel with a lattice constant of $3.5228 \AA{ }^{26}$ an $\mathrm{NaCl}$ type structure of $\mathrm{NiO}$ with a lattice constant of 4.168 $\AA^{27}$ and a monoclinic structure of $\mathrm{NiWO}_{4}$ with $\mathrm{a}=4.5992 \AA, \mathrm{b}=5.6606 \AA, \mathrm{c}=4.9068 \AA$ and $B=90.03^{\circ}$ were used. ${ }^{17,18}$ The peak positions were computed by the software POWDERCELL 2.3. ${ }^{28}$ The in-plane alignments of the different types of crystallites relative to each other were determined by pole figure measurements. ${ }^{29}$ The experimentally observed pole directions (net plane normals) were compared with stereograms using the software STEREOPOLE. ${ }^{30}$

The $\mathrm{Ni}(110)$ surface was cleaned by cycles of Ar ion sputtering (1.5 keV) and annealing to $1000 \mathrm{~K}$. In order to remove residual carbon contaminations the Ni crystal was exposed to oxygen (pressure of up to $1 \times 10^{-7}$ mbar) at $570 \mathrm{~K}$, followed by a brief flash to $1000 \mathrm{~K}$ in UHV. Surface order and cleanliness were monitored by LEED, STM and AES and XPS. The $\mathrm{NiWO}_{4}(100)$ films have been prepared by a three-step procedure. First, the Ni(110) surface has been oxidized in $5 \times 10^{-6}$ mbar $\mathrm{O}_{2}$ at $773 \mathrm{~K}$ for 10 min to produce a $\mathrm{NiO}(100)$ layer ${ }^{31}$ with a thickness of $\sim 10 \AA$, as established by XPS (see below). In a second step, $\left(\mathrm{WO}_{3}\right)_{3}$ clusters from a molecular beam ${ }^{21}$ have been deposited in UHV onto the $\mathrm{NiO}$ film at $300 \mathrm{~K}$. Finally, the mixed oxide film has been subjected to oxidative annealing in $5 \times 10^{-6} \mathrm{mbar}_{2}$ at $973 \mathrm{~K}$ for $15 \mathrm{~min}$. The last step was crucial to initiate the solid-state reaction between the binary $\mathrm{NiO}$ and $\left(\mathrm{WO}_{3}\right)_{3}$ phases, forming the ternary $\mathrm{NiWO}_{4}$ phase. The latter was found to exhibit a moderate structural order in STM, but annealing in UHV to $823 \mathrm{~K}$ resulted in better ordered films. The $\left(\mathrm{WO}_{3}\right)_{3}$ clusters beam was generated by thermal sublimation of $\mathrm{WO}_{3}$ powder at $1300 \mathrm{~K}$ in a thermal or e-beam evaporator, with the evaporation flux monitored by a quartz microbalance. The $\mathrm{NiWO}_{4}$ coverage, cited in the text, is set equal to the $\left(\mathrm{WO}_{3}\right)_{3}$ coverage measured in the quartz microbalance, with 1 monolayer equivalent (MLE) $\left(\mathrm{WO}_{3}\right)_{3}$ corresponding to the density of the surface atoms of $\mathrm{Ni}(110)$, i.e. $1.14 \times 10^{15}$ atoms $\mathrm{cm}^{-2}$.

DFT calculations were performed with the Vienna Ab-initio Simulation Package (VASP) ${ }^{32}$ using the Projector Augmented Wave (PAW) method ${ }^{33}$ to represent the electron-core 
interaction. Standard Ni and W, and soft oxygen (energy cutoff of $270 \mathrm{eV}$ ) pseudopotentials provided by VASP were used. The typical imprecision with respect to standard oxygen pseudopotential (energy cutoff of $400 \mathrm{eV}$ ) is of $0.01 \AA$ (bulk $\mathrm{NiWO}_{4}$ lattice parameters) and $0.01 \mathrm{~J} / \mathrm{m}^{2}\left[(1 \mathrm{x} 1)-\mathrm{NiWO}_{4}(100)\right.$ surface energies]. The Perdew-Wang 91 (PW91) ${ }^{34}$ gradientcorrected exchange-correlation functional was employed, within the DFT+U approach as proposed by Dudarev, ${ }^{35}$ with $\mathrm{U}-\mathrm{J}=6 \mathrm{eV}$ for both $\mathrm{Ni}$ and $\mathrm{W}$, in order to improve the description of the bulk band gap $\mathrm{E}_{\mathrm{g}}$. The calculated bulk lattice parameters $a=4.65 \AA, b=$ $5.72 \AA$ and $c=5.02 \AA$ are in good agreement with the experimental ones. ${ }^{17}$ Considering the very small distortion of the monoclinic cell with respect to orthorhombicity, in all the following, we have assumed that $\beta=90^{\circ}$.

$\mathrm{NiWO}_{4}$ has an antiferromagnetic insulating ground state, associated to a doubling of the unit cell along the a axis. The present DFT+U settings allow to well reproduce this ground state and produce a density of states in agreement with hybrid DFT simulation of bulk $\mathrm{NiWO}_{4}{ }^{36}$ The calculated band gap width $E_{\mathrm{g}}\left(\mathrm{E}_{\mathrm{g}}=3 \mathrm{eV}\right)$ is significantly larger than the GGA value of $0.9 \mathrm{eV}$ and close to the experimental $\mathrm{E}_{\mathrm{g}}=3.6 \mathrm{eV} \cdot{ }^{37}$ Reproducing a correct band gap is required to correctly describe the iono-covalent character of the cation-oxygen bonds, i.e. the electron distribution in the system, ${ }^{38}$ as well as a correct ordering of polar versus non-polar surface energies. ${ }^{39}$

A sketch of the wolframite structure is shown in Figure 1, using VESTA. ${ }^{40}$ It is built from distorted $\mathrm{NiO}_{6}$ and $\mathrm{WO}_{6}$ octahedra, sharing edges, and forming zig-zag chains along the $\mathrm{c}$ axis. Structurally inequivalent oxygen atoms exist in the structure, half of them being bound to $1 \mathrm{~W}$ and $2 \mathrm{Ni}$, and the other half to $2 \mathrm{~W}$ and $1 \mathrm{Ni}$. This results in inequivalent $\mathrm{Ni}-\mathrm{O}$ and $\mathrm{W}$ $\mathrm{O}$ distances. The Ni-O distances are not very different from each other $(2.09 \AA, 2.08 \AA$ and $2.08 \AA$, two of each type), while the $\mathrm{WO}_{6}$ octahedra are much more distorted $(2.12 \AA, 1.95 \AA$ and $1.84 \AA$ ).
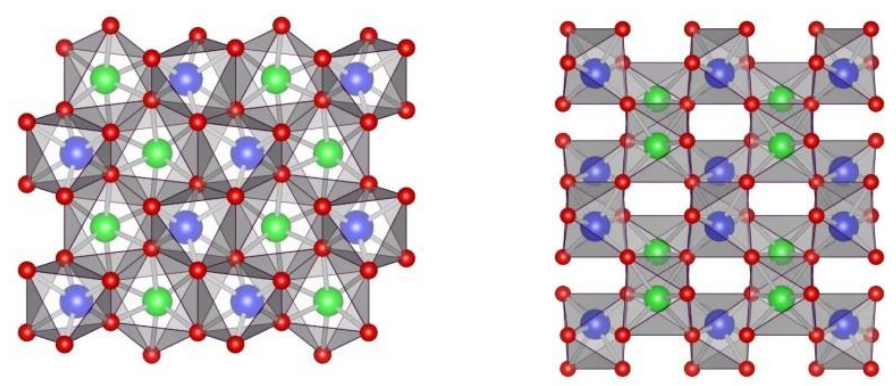

Figure 1. The NiWO4 bulk structure (W-blue, Ni-green, O-red) seen perpendicular to the $a$ (left) and $c$ (right) axes 


\section{EXPERIMENTAL RESULTS}

\section{A. X-ray photoelectron spectroscopy characterization}

The chemical composition and electronic structure changes occuring during the reaction of 5 MLE $\left(\mathrm{WO}_{3}\right)_{3}$ clusters with the $\mathrm{NiO}(100)$ film, supported on the $\mathrm{Ni}(110)$ surface, have been followed by recording XPS spectra in the Ni 2p, O 1s and W $4 \mathrm{f}$ core level and valence band regions, the results are presented in Fig. 2 . The $\mathrm{Ni} 2 \mathrm{p}_{3 / 2}$ spectrum of the clean $\mathrm{Ni}(110)$ surface (bottom spectrum in Fig. 2a) contains a main emission line with a binding energy (BE) of $852.6 \mathrm{eV}\left(\right.$ marked $\mathrm{Ni}^{0}$ ) and a satellite peak (marked $\mathrm{S}$ ) shifted by $\sim+6 \mathrm{eV}$, which is due to a two hole $c^{-1} 3 d^{9} 4 s^{2}\left(c^{-1}\right.$ is a core hole) final state effect. ${ }^{41}$ The $\mathrm{NiO}(100)$ film is spectroscopically well distinguished from the $\mathrm{Ni}(110)$ substrate and displays a characteristic $\mathrm{Ni} 2 \mathrm{p}_{3 / 2}$ line shape (Fig. 2a, middle spectrum), which can been fitted with four core-level components with BEs of $854.4 \mathrm{eV}$ (marked A), $856.1 \mathrm{eV}(\mathbf{B}), 861.0 \mathrm{eV}$ (C) and $862.9 \mathrm{eV}$ (D), typical for $\mathrm{Ni}^{2+}$ species in bulk NiO. ${ }^{42}$ The lowest $\mathrm{BE}$ main line $\mathbf{A}$ has been assigned to a $\mathrm{c}^{-1} 3 \mathrm{~d}^{9} \mathrm{~L}^{-1}$ final state, where $\mathrm{c}^{-1}$ and $\mathrm{L}^{-1}$ refer to a hole in the $2 \mathrm{p}$ core level and the ligand band, respectively, whereas the component $\mathbf{B}$ has been ascribed to a non-local screening process from neighbouring $\mathrm{NiO}_{6}$ units ${ }^{43}$ and/or surface effects. ${ }^{44}$ The emission structures at the higher binding energy side, $\mathbf{C}$ and $\mathbf{D}$, correspond to a $\mathrm{c}^{-1} 3 \mathrm{~d}^{10} \mathrm{~L}^{-2}$ and $\mathrm{c}^{-1} 3 \mathrm{~d}^{8}$ final states, respectively. ${ }^{42}$ Some remnant intensity of the underlying Ni substrate can be also seen at the low $\mathrm{BE}$ side of the $\mathrm{Ni} 2 \mathrm{p}_{3 / 2}$ spectrum of the $\mathrm{NiO}$ film, which proofs useful in determining the thickness of the latter. From the attenuation of the substrate $\mathrm{Ni}^{0}$ signal by the $\mathrm{NiO}$ film and using the electron inelastic mean free length of $4.9 \AA$ for $\mathrm{NiO}$ at a kinetic energy of $100 \mathrm{eV}, 45$ we estimate a thickness of $10.5 \AA$, which correspond to $\sim 5 \mathrm{NiO}$ layers. The $\mathrm{O} 1 \mathrm{~s}$ spectrum of the $\mathrm{NiO}$ film (Fig. 1b, bottom curve) contains a single peak with a maximum at a binding energy of $529.9 \mathrm{eV}$, in agreement with similar values reported in the literature. ${ }^{46,47}$ The corresponding valence band spectrum (Fig. 2d, middle curve) is also typical for $\mathrm{NiO}(100)$ surfaces of bulk crystals ${ }^{48}$ or thin films, ${ }^{49}$ containing a doublet emission structure at $2.5 \mathrm{eV}$ and $4.1 \mathrm{eV}$ due to a multiplet of hybridized $3 \mathrm{~d}^{8} \mathrm{~L}^{-1}$ final states, a broad band between $5 \mathrm{eV}$ and $7 \mathrm{eV}$, related to $\mathrm{O} 2 \mathrm{p}$-derived states, and a satellite peak around $10 \mathrm{eV}$, which has been attributed to emission from unscreened $3 \mathrm{~d}^{7}$ final states.

The deposition of $5 \mathrm{MLE}\left(\mathrm{WO}_{3}\right)_{3}$ onto the $\mathrm{NiO}(100)$ film on $\mathrm{Ni}(110)$ at room temperature results in the formation of a layer of intact $\left(\mathrm{WO}_{3}\right)_{3}$ clusters, as confirmed by the $\mathrm{W}$ 4f (Fig. 2c, bottom curve) and $\mathrm{O}$ 1s (Fig. 1b, middle curve) spectra. The $\mathrm{W}$ 4f spectrum of the $\left(\mathrm{WO}_{3}\right)_{3}$ clusters has been fitted with a single $\mathrm{W} 4 \mathrm{f}_{7 / 2}-\mathrm{W} 4 \mathrm{f}_{5 / 2}$ doublet peak, with BEs of $35.9 \mathrm{eV}$ and 
$38.1 \mathrm{eV}$, respectively, which are compatible with the oxidation state $6+$ of the $\mathrm{W}$ atoms in the intact $\left(\mathrm{WO}_{3}\right)_{3}$ clusters. ${ }^{21}$ The $\left(\mathrm{WO}_{3}\right)_{3}$ layer exhibits no long-range order (as confirmed by LEED), therefore the $\mathrm{W} 4 \mathrm{f}$ spectrum displays a broad line shape with a full width at half

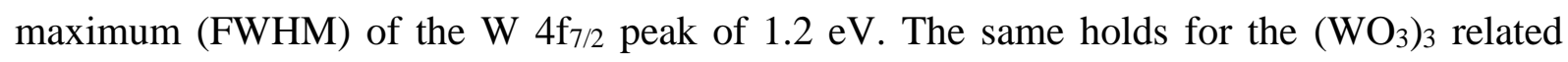
component in the corresponding $\mathrm{O}$ 1s spectrum, which is characterized by broad (FWHM = $2.2 \mathrm{eV}$ ) line shape with a maximum at $530.8 \mathrm{eV}$, and is energetically well separated and distinguished from the attenuated $\mathrm{O} 1 \mathrm{~s}$ peak of the underlying $\mathrm{NiO}$ film at $529.9 \mathrm{eV}$.
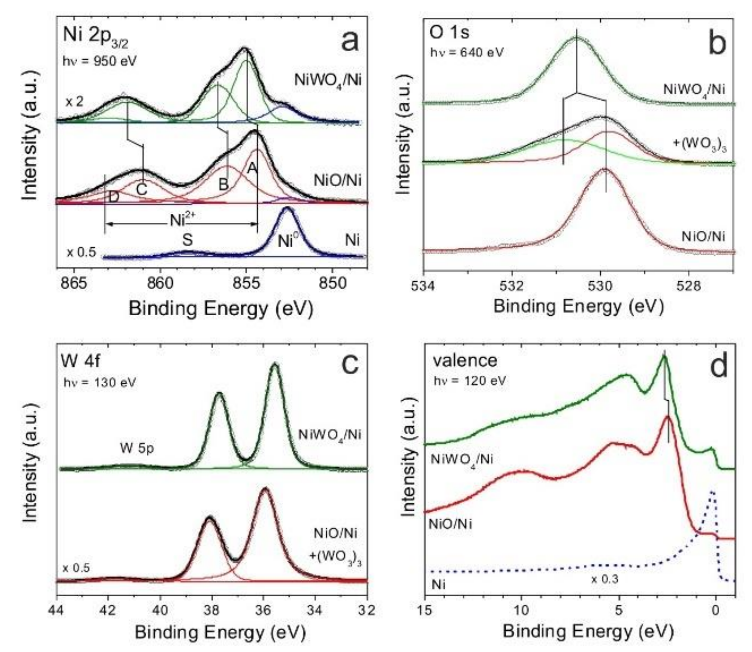

Figure 2. Ni 2p (a), O 1s (b), W 4f (c) core level and valence band (d) spectra of the different surfaces investigated: the $\mathrm{Ni}(110)$ surface, the $\mathrm{NiO}(100)$ film on $\mathrm{Ni}(110)$, the $\left(\mathrm{WO}_{3}\right)_{3}$ clusters on $\mathrm{NiO}$, and the $\mathrm{NiWO}_{4}$ film on $\mathrm{Ni}(110)$. The core level spectra have been decomposed into different components, described in the text.

After the thermal treatment of the mixed $\left(\mathrm{WO}_{3}\right)_{3}-\mathrm{NiO}$ layer at $973 \mathrm{~K}$ in $5 \times 10^{-6}$ mbar $\mathrm{O}_{2}$ distinct changes are observed in all analyzed XPS spectra (top curves in Fig. 2), reflecting the generation of a new oxide phase, which has been unambiguously identified as $\mathrm{NiWO}_{4}$ in the XRD measurements, discussed below. The $\mathrm{W} 4 \mathrm{f}$ spectrum contains a single $\mathrm{W} 4 \mathrm{f}_{7 / 2}-\mathrm{W} 4 \mathrm{f}_{5 / 2}$ doublet peak, with the $\mathrm{W} 4 \mathrm{f}_{7 / 2}$ peak located at $35.6 \mathrm{eV}$, in good agreement with binding energy values reported for $\mathrm{NiWO}_{4}$ compounds. ${ }^{16,50,51}$ The corresponding $\mathrm{O}$ 1s spectrum contains a single component with a $\mathrm{BE}$ of $530.3 \mathrm{eV}$, which is also compatible with $\mathrm{NiWO}_{4}$ literature data. ${ }^{16}$ The absence of $\mathrm{NiO}$ - and $\left(\mathrm{WO}_{3}\right)_{3}$ - related core-level components in the $\mathrm{O}$ 1s spectrum suggests that the original binary oxide phases have completely reacted together to

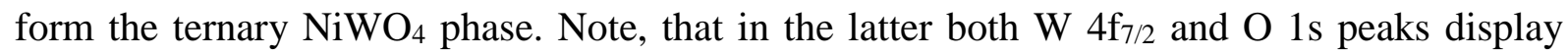
markedly narrowed line shapes with respect to corresponding spectra of the $\left(\mathrm{WO}_{3}\right)_{3}$ clusters, with FWHM of $0.75 \mathrm{eV}$ and $1.25 \mathrm{eV}$, respectively, which is fully in line with the crystalline 
nature of the $\mathrm{NiWO}_{4}$ phase, as reported below. The $\mathrm{Ni}^{2+}$ fine structure is generally maintained in the Ni 2p $\mathrm{p}_{3 / 2}$ spectrum of the $\mathrm{NiWO}_{4}$ film (Fig. 2a, top spectrum), but the peaks $\mathbf{A}$ and $\mathbf{B}$ are now shifted by $+0.6 \mathrm{eV}$, the peak $\mathrm{C}$ by $\sim+1 \mathrm{eV}$. These shifts are well documented in the literature ${ }^{16,51}$ and reflect the different local chemical environment of the $\mathrm{Ni}^{2+}$ species in the $\mathrm{NiWO}_{4}$ phase, as compared to $\mathrm{NiO}$. The substrate $\mathrm{Ni}^{0}$ signal in the $\mathrm{Ni} 2 \mathrm{p}$ spectrum of the $\mathrm{NiWO}_{4}$ covered $\mathrm{Ni}(110)$ surface can again assist to estimate the average thickness of the $\mathrm{NiWO}_{4}$ layer. Using the electron inelastic mean free length of $4.6 \AA$ for $\mathrm{NiWO}_{4}$ at kinetic energy of $100 \mathrm{eV},{ }^{45}$ the NiWO4 thickness is determined to be $\sim 9.8 \AA$. Note that the intensity decrease of the $\mathrm{W} 4 \mathrm{f}$ and $\mathrm{Ni} 2 \mathrm{p}$ peaks in the $\mathrm{NiWO}_{4}$ spectra, with respect to the corresponding spectra of the $\left(\mathrm{WO}_{3}\right)_{3}$ and $\mathrm{NiO}$ layers, respectively, is mostly due to the three-dimensional character of the $\mathrm{NiWO}_{4}$ film growth, as established by STM (see e.g. Fig. 5 ), but some sublimation of $\left(\mathrm{WO}_{3}\right)_{3}$ and/or reduction of the $\mathrm{NiO}$ layer at the high reaction temperature $(923 \mathrm{~K})$ cannot be excluded. Finally, the valence band spectrum (top curve in Fig. 2d) reflects the changes in the electronic band structure accompanying the formation of the $\mathrm{NiWO}_{4}$ layer. Here, mainly hybridized Ni $3 \mathrm{~d}$ and $\mathrm{O} 2 \mathrm{p}$ emissions are present. The $3 \mathrm{~d}^{8} \mathrm{~L}^{-1}$ multiplet structure at the valence band maximum is shifted in $\mathrm{NiWO}_{4}$ by $+0.3 \mathrm{eV}$ and partially overlaps with the $\mathrm{O} 2 \mathrm{p}$ band, which can be ascribed to the modified ligand field in the $\mathrm{NiWO}_{4}$ layer with respect to $\mathrm{NiO}$. The broad satellite structure around $10 \mathrm{eV}$ is strongly attenuated, indicating a smaller weight of the unscreened $3 \mathrm{~d}^{7}$ emission channel in $\mathrm{NiWO}_{4}$. On annealing in UHV to $823 \mathrm{~K}$, which was employed to improve the structural order of the $\mathrm{NiWO}_{4}$ layer, no significant changes in all XPS spectra were observed, besides some decrease of the $\mathrm{W} 4 \mathrm{f}$ and $\mathrm{Ni}^{2+}$ intensities, accompanied by an increase of the substrate $\mathrm{Ni}^{0}$ signal, which we attribute to morphological changes in the oxide overlayer.

\section{B. X-ray diffraction analysis}

We have performed ex-situ XRD measurements of the 5 MLE $\mathrm{NiWO}_{4}$ film on $\mathrm{Ni}(110)$, which has been prepared in UHV and characterized in-situ with STM (see Fig. 5b). The sample has then been taken out and left for one night in air, and afterwards inserted back in the UHV chamber. No differences in the film morphology and structure were found in STM and LEED, proving that the $\mathrm{NiWO}_{4}$ film is robust and stable in air.

A specular x-ray diffraction pattern of the sample is depicted in Fig. 3a. Three different types of crystal structures are observed. The $\mathrm{Ni}(110)$ single crystal substrate generates a peak at $\mathrm{q}_{\mathrm{z}}=$ 
$2.52 \AA^{-1}$, which originates from the (110) plane and corresponds to the 220 reflection from radiation with the wavelength $\lambda / 2$. The $\mathrm{NiWO}_{4}$ crystallites contribute with the 100 and 200 diffraction peaks and small traces of the 011 peak; from the $\mathrm{NiO}$ phase the 200 peak is observed. These results reveal that the $\mathrm{NiWO}_{4}(100)$ plane (and/or (100) plane), as well as the $\mathrm{NiO}(100)$ plane, are parallel to the $\mathrm{Ni}(110)$ surface. We note parenthetically that the $\mathrm{NiO}$ phase has been formed during the exposure of the sample in air as a result of oxidation of the $\mathrm{Ni}(110)$ substrate. This is due to the fact that the $\mathrm{NiWO}_{4}$ film, although thick enough to generate x-ray diffraction reflections, is not completely closed (see e.g. STM image in Fig $5 b)$. In a next step, the x-ray diffraction pole figures were investigated. From each crystalline phase a set of two individual pole figures was measured. The 111 pole figure of the nickel substrate is shown in Fig. 3b. The experimentally observed pole densities are explained by the peaks 111 and 11․ In a subsequent step the in-plane direction [110] of the Ni(110) surface has been determined. A single pole figure of the $\mathrm{NiWO}_{4}$ crystallites is displayed in Fig. 3c. Two different alignments of the $\mathrm{NiWO}_{4}$ crystallites (marked by triangles up and triangles down, respectively) are required to explain the observed pole densities. In both cases either the [011] or [011] direction of $\mathrm{NiWO}_{4}$ phase is parallel to the [110] direction of the $\mathrm{Ni}(110)$ substrate, while either the (100) plane is parallel to the substrate surface (triangles down) or the (100) plane (triangles up). In summary, two different epitaxial alignments of the $\mathrm{NiWO}_{4}$ crystallites relative to the $\mathrm{Ni}(110)$ surface are observed by the x-ray diffraction: either $\mathrm{NiWO}_{4}(100)$ or $\mathrm{NiWO}_{4}\left(\underline{100)} \| \mathrm{Ni}(110)\right.$ and either $\mathrm{NiWO}_{4}[011]$ or $\mathrm{NiWO}_{4}[011] \| \mathrm{Ni}[\underline{110}]$.
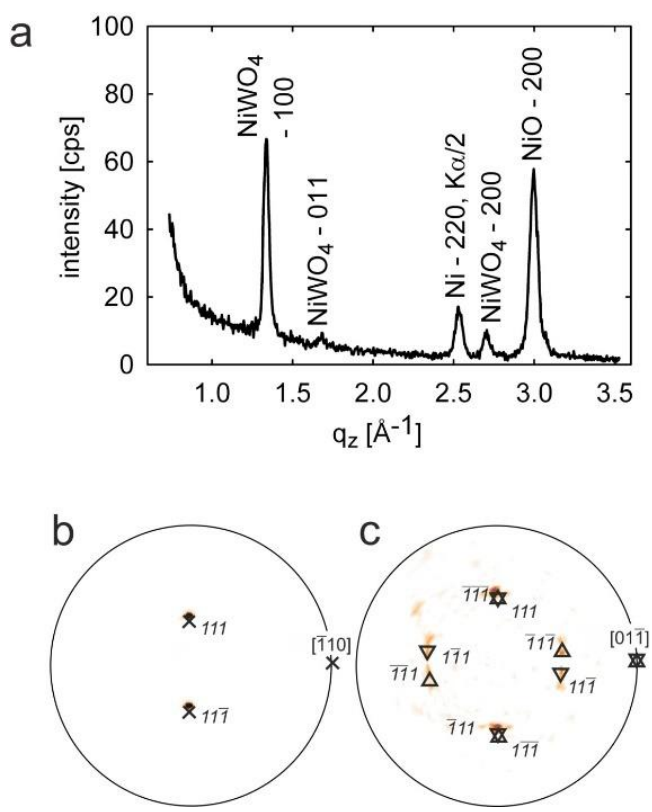

Figure 3. (a) Specular x-ray diffraction scan of the $5 \mathrm{MLE} \mathrm{NiWO}_{4}$ film on $\mathrm{Ni}(110)$; (b) and (c) are $\mathrm{x}$ ray diffraction pole figures of the $\mathrm{Ni}$ substrate and $\mathrm{NiWO}_{4}$ film, respectively. 
The most important findings of the XRD analysis are summarized in Fig. 4. The crystal structure of $\mathrm{NiWO}_{4}$ is that of the mineral Wolframite, which is characterized by alternating layers of $\mathrm{Ni}$ and $\mathrm{W}$ atoms parallel to the (100) plane, separated by layers of quasi-hexagonally close packed oxygen atoms (Fig. 4a). The $\mathrm{NiWO}_{4}(100)$ surface plane, which according to the XRD data is parallel to the $\mathrm{Ni}(110)$ substrate, displays a rectangular unit cell with unit cell vectors $\mathrm{b}=5.6606 \AA$ and $\mathrm{c}=4.9068 \AA$, as exemplified in Fig. 4b. The diagonals of the unit cell are running along the $\langle 011\rangle \mathrm{NiWO}_{4}$ directions, and these are parallel to the $\langle 110\rangle$ $\mathrm{Ni}(110)$ substrate directions, as established in the pole figure analysis. This epitaxial alignment is most likely a result of the favorable matching of the $\mathrm{NiWO}_{4}(100)$ and $\mathrm{Ni}(110)$ lattices in the $\mathrm{Ni}[110]$ direction (Fig. 4c): the diagonals of the $\mathrm{NiWO}_{4}(100)$ unit cell $(7.49 \AA$ ) fit almost perfectly (mismatch of only $0.25 \%$ ) to 3 times the $\mathrm{Ni}$ atom spacing in the $\mathrm{Ni}[110]$ direction $(7.47 \AA)$.

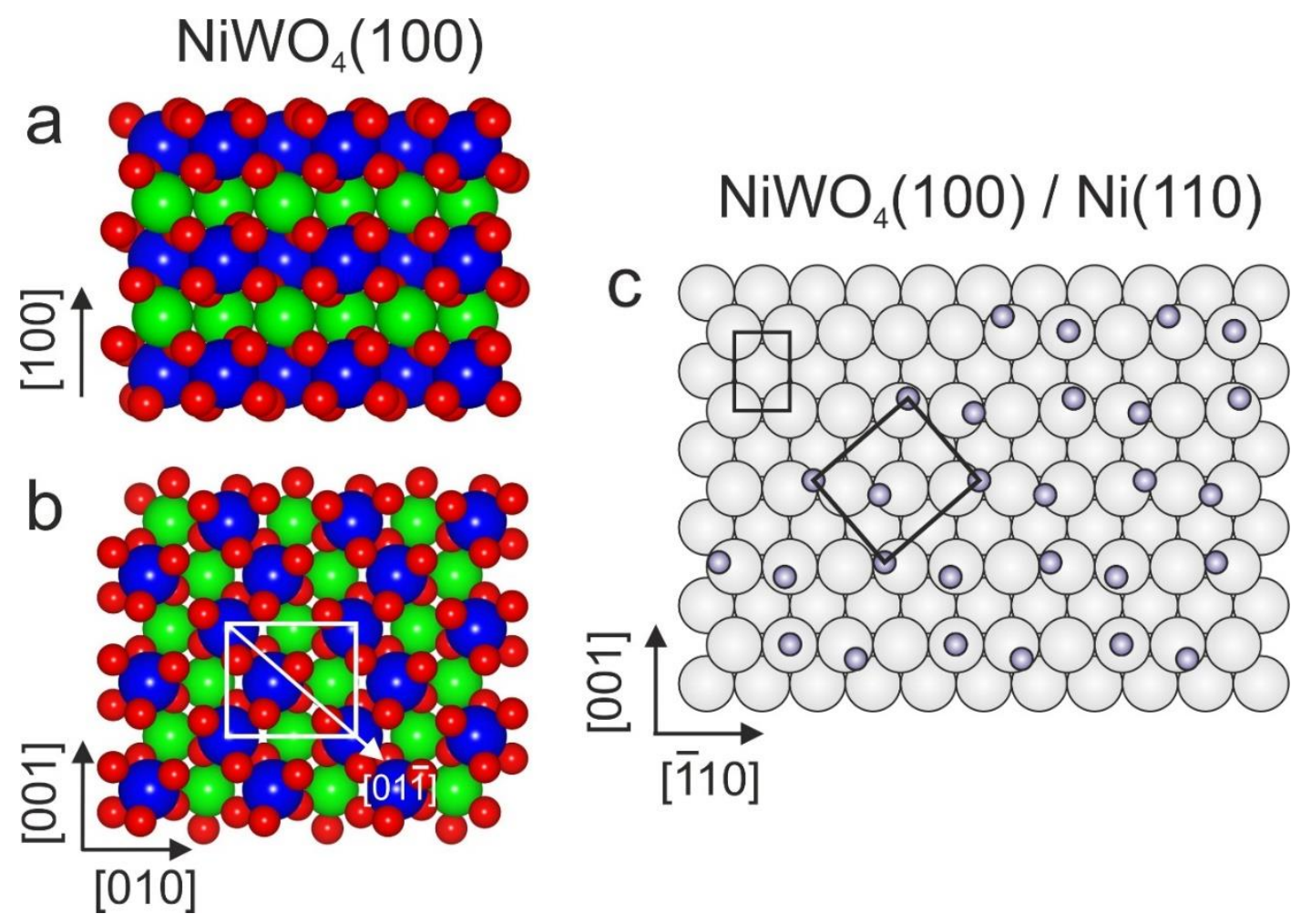

Figure 4. Side (a) and top (b) view of the $\mathrm{NiWO}_{4}$ structure along the [100] direction. The $\mathrm{NiWO}_{4}(100)$ unit cell and the main crystallographic directions are indicated (W-blue, Ni-green, O-red); (c) lattice model visualizing the epitaxial alignment of the $\mathrm{NiWO}_{4}(100)$ and $\mathrm{Ni}(110)$ lattices, with the corresponding unit cells indicated. The large grey spheres correspond to the substrate $\mathrm{Ni}$ atoms, the small blue spheres to the $\mathrm{NiWO}_{4}$ film Ni (or W) atoms. 


\section{Surface morphology and structure}

The large-scale STM images in Fig. 5(a,b) reveal that the $\mathrm{NiWO}_{4}$ film grows in a threedimensional (3D) manner on the $\mathrm{Ni}(110)$ substrate. At a $\left(\mathrm{WO}_{3}\right)_{3}$ coverage of 2 MLE wellfaceted crystallites form (Fig. 5a), whose height varies between 2 and $5 \mathrm{~nm}$. The most often occurring facets are the top one (indicated A) and the side facet B, which are both atomically flat and exhibit characteristic stripe patterns, with the stripes running along the $\mathrm{Ni}[110]$ substrate direction, as discussed in more detail below. The top facet is separated from the side facets by straight edges, which include angles compatible with the angles between highsymmetry directions parallel to $\mathrm{NiWO}_{4}(100)$ planes, as sketched in Fig. 5c. In particular, the $\mathrm{NiWO}_{4}[011]$ direction is parallel to the Ni[110] substrate direction, which is in line with the results of the XRD analysis. The edge parallel to the $\mathrm{NiWO}_{4}[011]$ direction is also the one, where the top facet A and the side facet B meet each other.
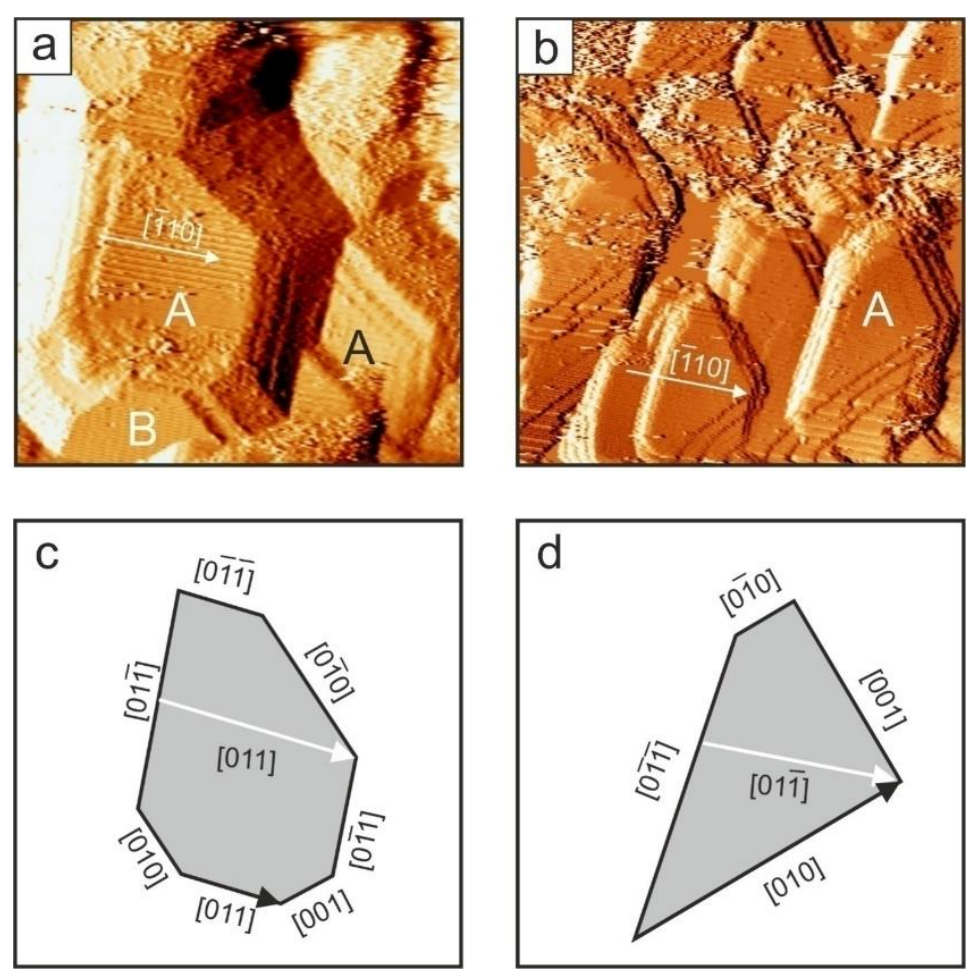

Figure 5. Large-scale STM images ( $\left.1000 \times 1000 \AA^{2}, \mathrm{U}=+1.0 \mathrm{~V}, \mathrm{I}=10 \mathrm{pA}\right)$ of 2 MLE (a) and 5 MLE (b) $\mathrm{NiWO}_{4}$ films on $\mathrm{Ni}(110)$. The dominant facets are indicated A (top) and B (side); (c) and (d) are schematic drawings, highlighting the edges (black line) between the top (gray shaded) and the side facets in the STM images in (a) and (b), respectively. The black arrows indicate the rotation sense of the edge directions, while the white arrows indicate which $\mathrm{NiWO}_{4}<011>$ direction is parallel to the $\mathrm{Ni}$ substrate [110] direction. 
With increasing $\left(\mathrm{WO}_{3}\right)_{3}$ coverage the density of the $\mathrm{NiWO}_{4}$ crystallites increases and eventually at a coverage above 5 MLE they merge forming more planar, but discontinuous $\mathrm{NiWO}_{4}$ film with a RMS roughness of $0.5 \mathrm{~nm}$ (Fig. 5b). This film morphology is possibly the reason for the oxidation of the underlying $\mathrm{Ni}(110)$ substrate to $\mathrm{NiO}$ upon exposing the $\mathrm{NiWO}_{4}$ film to air, as observed in the XRD. The surface of the $\mathrm{NiWO}_{4}$ film is terminated exclusively by the A-type facets, which are separated by straight step edges including similar characteristic angles as in Fig. 5a. The analysis of these angles (see the sketch in Fig. 5d) revealed that the stripes of the A-facet (which are parallel to the Ni[110] direction) are now aligned along the other diagonal of the $\mathrm{NiWO}_{4}(100)$ unit cell, which is in the $\mathrm{NiWO}_{4}[01 \underline{1}]$ direction, in good agreement with the XRD analysis.

At intermediate oxide coverages (between 2 and 5 MLE) the $\mathrm{NiWO}_{4}$ film displays an intriguing growth pattern reminiscent of the "hill-and-valley" reconstruction of vicinal surfaces, which is driven by the lowering of the surface energy. Figure 6a shows an STM image of a $3.3 \mathrm{MLE} \mathrm{NiWO}_{4}$ film surface (Fig. $6 \mathrm{~b}$ is a 3D view of the image in Fig. 6a), containing a staircase of alternating A- and B- facets, separated by atomically sharp and straight edges running in the Ni[110] direction. The A-facets are distinguished in STM by their single stripe pattern, whereas the B-facets exhibit a double stripe structure (see Fig. 7 for more detail). A line profile taken along the A-B-A-B staircase is plotted in Fig. $6 \mathrm{c}$ and allows us to determine the angle between the A- and B-facets, which measures $6^{\circ} \pm 1^{\circ}$.
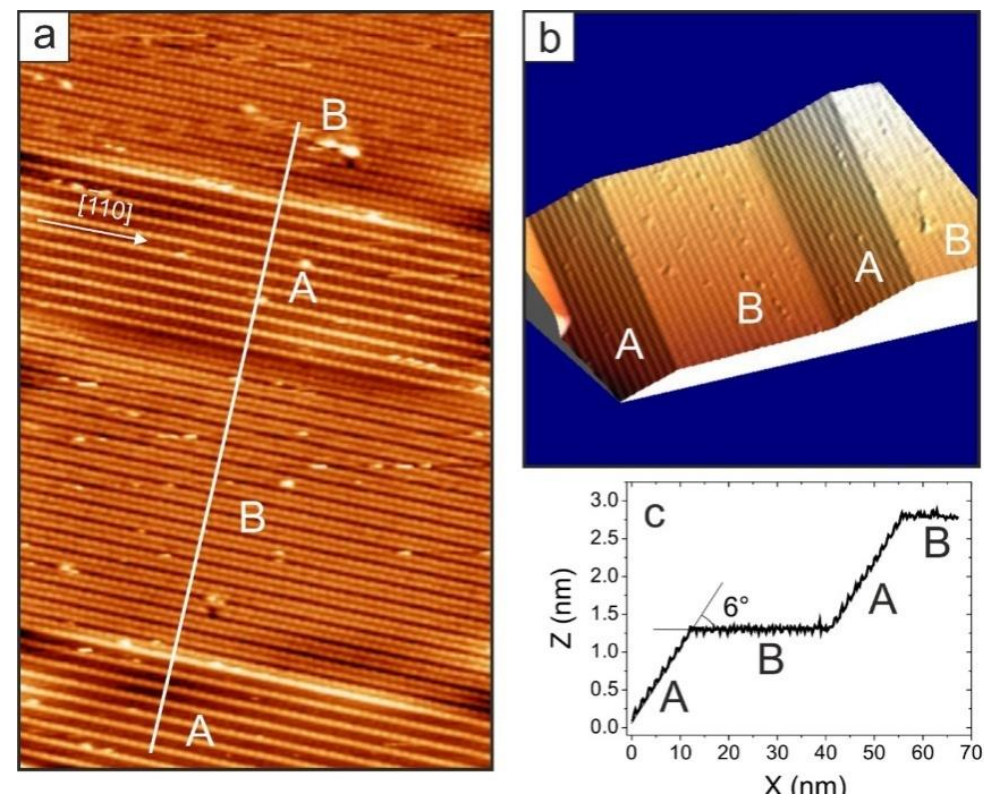

Figure 6. (a) STM image of a $3.3 \mathrm{MLE} \mathrm{NiWO}_{4}$ film on $\mathrm{Ni}(110)\left(450 \times 700 \AA^{2}, \mathrm{U}=+0.5 \mathrm{~V}, \mathrm{I}=50\right.$ $\mathrm{pA}$ ). The A and B facets are indicated; (b) 3D view of the STM image in (a) to emphasize the staircase film morphology; (c) line profile across the $\mathrm{A}$ - and $\mathrm{B}$ - facets, including an angle of $6^{\circ}$. 
The high-resolution STM images of the A- and B- facets, presented in Fig. 7a and 7b, respectively, assist identifying their geometrical structure and orientation. The A - facet displays single stripes oriented along the Ni[110] direction with a periodicity of $15.8 \AA \pm 0.2$ $\AA$ across the stripes (see line profile 2-2' in Fig. 7a and 7c). The stripes consist of a periodic array of bright protrusions, elongated along the stripe direction, with a separation of $7.6 \AA \pm$ $0.2 \AA$ (line profile 1-1' in Fig. 7a and 7c). These two periodicities define an oblique unit cell for the $\mathrm{A}-$ facet (indicated with a black solid line in Fig. 6a) with an obtuse angle of $100^{\circ} \pm$ $2^{\circ}$. Between two neighboring stripes a row of elongated maxima with a darker contrast can be also recognized in both the STM image (Fig. 7a) and the line profile 2-2' (Fig. 7c). The B facet shows a more complex appearance in the STM images (Fig. 6b): it consists of double zig-zag stripes running also parallel to the Ni[110] direction, with the distance between the maxima along the stripe direction being the same as in the $\mathrm{A}$ - facet, i.e. $7.6 \AA$, but the periodicity across the stripes is twice larger, i.e. $31.5 \AA$. The corresponding unit cell is drawn with the solid line on the STM image in Fig. 7b, with the two unit cell vectors including the same angle of $100^{\circ}$, as in the facet A. We note in passing that the STM images of the A- and B-facets show no significant sample bias and polarity dependence in the range $(-2.0$ to +2.0 V), with the best contrast achieved for the A-facet at positive sample bias, and for the B-facet at negative sample bias.
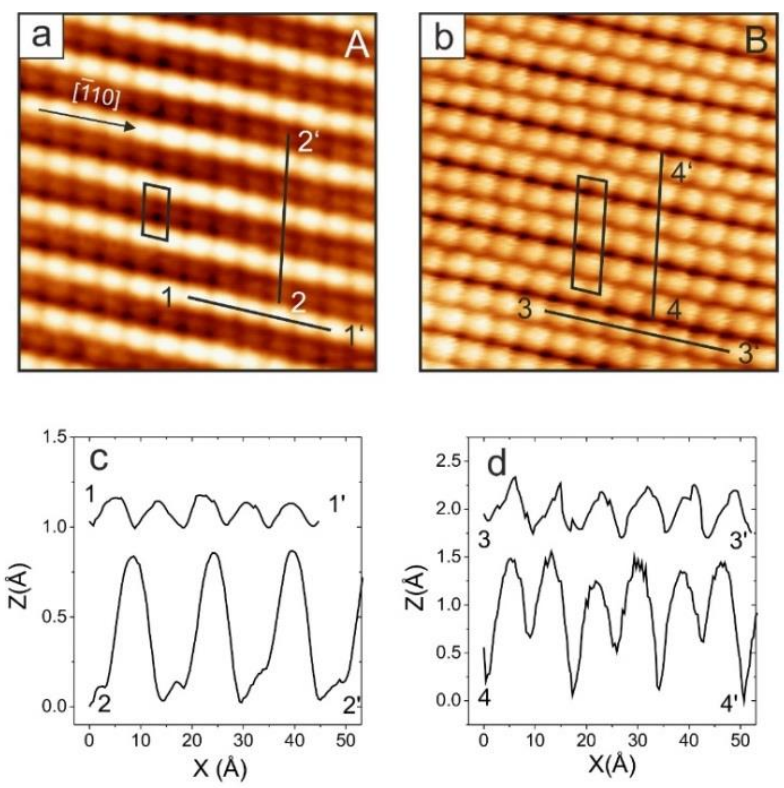

Figure 7. High-resolution STM images of the A (a) and B (b) facets: (a) $100 \times 100 \AA^{2}, U=+1.0 \mathrm{~V}, \mathrm{I}=$ $100 \mathrm{pA}$, (b) $100 \times 100 \AA^{2}, \mathrm{U}=-1.0 \mathrm{~V}, \mathrm{I}=150 \mathrm{pA}$. The corresponding unit cells are indicated with black lines; (c) and (d) display line profiles taken along the directions indicated in (a) and (b) respectively. 


\section{COMPUTATIONAL RESULTS}

To the best of our knowledge, no $\mathrm{NiWO}_{4}$ surface has been theoretically studied in the past. We have thus made a preliminary assessment of the stability of several $\mathrm{NiWO}_{4}$ low index surfaces, prior to focusing on the polar (100) orientation.

\section{A. $\mathrm{NiWO}_{4}$ low energy surfaces}

We have considered a series of low Miller index surfaces, restricting ourselves to configurations with (1x1) surface unit cells. In Table 1 we report results on the most stable of them, in the order of increasing surface energy. The corresponding atomic surface structures are given in Figure S1 (Supplementary material).

\begin{tabular}{|c|c|c|c|c|c|}
\hline $\begin{array}{c}(1 \mathrm{x} 1) \\
\text { Surface }\end{array}$ & $\begin{array}{c}\text { Es } \\
\left(\mathrm{J} / \mathrm{m}^{2}\right)\end{array}$ & $\begin{array}{c}\text { Polar } \\
\text { character }\end{array}$ & $\begin{array}{c}2 \mathrm{D} \text { cell } \\
\operatorname{area}\left(\AA^{2}\right)\end{array}$ & $\mathrm{N}_{\text {Ni-O }}$ broken & N w-O broken \\
\hline$(010)$ & 0.62 & $\mathrm{NP}$ & 46.66 & $4(0.086)$ & 0 \\
\hline$(210)$ & 0.77 & $\mathrm{NP}$ & 73.94 & $6(0.081)$ & 0 \\
\hline$(2 \underline{11})$ & 0.77 & $\mathrm{NP}$ & 45.54 & $2(0.044)$ & $1(0.022)$ \\
\hline$(0 \underline{11})$ & 0.82 & $\mathrm{NP}$ & 70.75 & $4(0.056)$ & $2(0.028)$ \\
\hline$(100) \mathrm{Ni}$ & 1.01 & $\mathrm{P}$ & 28.68 & $3(0.105)$ & 0 \\
\hline$(201)$ & 1.06 & $\mathrm{NP}$ & 78.23 & $4(0.051)$ & $2(0.025)$ \\
\hline$(100) \mathrm{W}$ & 1.10 & $\mathrm{P}$ & 28.68 & $2(0.070)$ & $2(0.070)$ \\
\hline$(101)$ & 1.18 & $\mathrm{P}$ & 60.43 & $3(0.050)$ & $2(0.033)$ \\
\hline$(001)$ & 1.26 & $\mathrm{NP}$ & 53.19 & $2(0.038)$ & $2(0.038)$ \\
\hline
\end{tabular}

Table 1. Most stable $\mathrm{NiWO}_{4}$ surfaces with low Miller indexes: their polar character $(\mathrm{NP}=$ non-polar, $\mathrm{P}=$ compensated polar), their surface energy (in $\mathrm{J} / \mathrm{m}^{2}$ ), the area of their $2 \mathrm{D}$ unit cell (in $\AA^{2}$ ), the number of broken $\mathrm{Ni}-\mathrm{O}$ and $\mathrm{W}-\mathrm{O}$ bonds per unit cell and per surface area (in parenthesis, in $\AA^{-2}$ ).

As a general trend, the orientations of lowest energy are non-polar and involve the smallest number of broken bonds per surface area. This is particularly clear in case of W-O bonds, and highlights their larger strength compared to the Ni-O bonds. As a consequence, the most stable surfaces are Ni-terminated. If $\mathrm{W}$ atoms are present in the outermost layers, they are bound to an oxo- ligand (e.g. the (210) surface) with a very short W-O bond ( $1.74 \AA$ ). We note that a simple picture with a constant ratio between the Ni-O and $\mathrm{W}-\mathrm{O}$ bond strengths cannot account for the complex hierarchy of the surface energies in Table 1, which is also 
influenced by fine details of surface bond relaxation and long range electrostatic effects. As a peculiarity of the wolframite structure, the surfaces of lowest Miller indexes have not necessarily the lowest density of broken bonds, and, as a corollary, not the lowest surface energy (e.g. the (100) and the (001) surfaces), at variance with simpler crystallographic structures.

The calculated relatively low stability of the (100) surfaces (to be discussed below) suggests that the large facets vicinal to the (100) orientation observed experimentally are either due to a kinetic hindrance or, more likely, to a limited thickness of the oxide film and to its substantial interaction with the metallic Ni substrate.

\section{B. NiWO4(100) surface}

The $\mathrm{NiWO}_{4}(100)$ surface is polar, according to Tasker's classification, ${ }^{52}$ because the repeat unit perpendicular to the surface consists of successive charged layers $2 \mathrm{Ni} / 4 \mathrm{O} / 2 \mathrm{~W} / 4 \mathrm{O}$, and thus bears a non-zero dipole moment. As a consequence, electrostatic stabilization requires compensating charges in the surface layers. Considering the absence of experimental evidence of changes of cation oxidation states, we will focus here on stabilization by nonstoichiometric surface reconstructions, which have proven to efficiently heal polarity. ${ }^{53,54}$

For the Ni and $\mathrm{W}$ terminations, the required compensating surface charge is equal to half the layer charge, so that, e.g., one half of surface cations have to be removed. Conversely, at the two nonequivalent oxygen terminations, either one or three out of four oxygen atoms per unit cell have to be removed, depending if the underlying layer is composed of $\mathrm{W}$ or of $\mathrm{Ni}$. We have analyzed these alternative surface terminations with stoichiometric bulk-cut slabs. They are symmetric when terminated by $\mathrm{Ni}$ or $\mathrm{W}$ (e.g., W/4O/2Ni/4O/.../2W/4O/2Ni/4O/W) and asymmetric for the oxygen terminations $(3 \mathrm{O} / 2 \mathrm{~W} / 4 \mathrm{O} / 2 \mathrm{Ni} / 4 \mathrm{O} / \ldots / 2 \mathrm{~W} / 4 \mathrm{O} / 2 \mathrm{Ni} / \mathrm{O})$. As a consequence, only the average surface energy of the oxygen terminations is obtained.

The most stable surface is Ni-terminated $\left(E_{\mathrm{s}}=1.01 \mathrm{~J} / \mathrm{m}^{2}\right)$, with only three broken Ni-O bonds per surface unit cell (Fig. 8, left panel). The surface Ni atoms undergo a noticeable inward relaxation which strongly shortens the three remaining Ni-O bonds (1.85 $\AA$ compared to 2.12 $\AA$ in the bulk) and leads to an energy lowering of nearly $80 \%$ (from $1.82 \mathrm{~J} / \mathrm{m}^{2}$ to $1.01 \mathrm{~J} / \mathrm{m}^{2}$ ). Much stronger atomic rearrangements take place at the $\mathrm{W}$ termination, where an oxygen atom bound to two subsurface Ni moves outwards and binds on-top the outermost W (Fig. 8, right panel). With respect to the unrelaxed termination, two $\mathrm{Ni}-\mathrm{O}$ bonds per unit cell are broken and one strong $\mathrm{W}=\mathrm{O}$ bond is formed with a length $(1.74 \AA)$ typical of a terminal oxo-ligand. ${ }^{55}$ 
Upon such rearrangement, the surface energy is divided by roughly a factor of 5 (from 5.64 $\mathrm{J} / \mathrm{m}^{2}$ to $1.10 \mathrm{~J} / \mathrm{m}^{2}$, which brings it close to, but slightly higher than, that of the $\mathrm{Ni}$ termination. At this point it is worth noting that the comparison between the $\mathrm{Ni}$ - and $\mathrm{W}=\mathrm{O}-$ terminated unrelaxed surface energies shows that the ratio between $\mathrm{W}-\mathrm{O}$ and $\mathrm{Ni}-\mathrm{O}$ bond strengths is roughly equal to 3 , consistently with the previous consideration of the relative stability of the different surface orientations (Table 1). As far as the oxygen terminations are concerned, due to the asymmetry of the two sides of the slab, only the average surface energy can be obtained without relying on grand potential analysis, which would be beyond the scope of the present work. Since their average surface energies are much higher than those of the Ni- or W-terminated surfaces (Table S1, Supplementary Material), the oxygen terminations will not be further discussed.
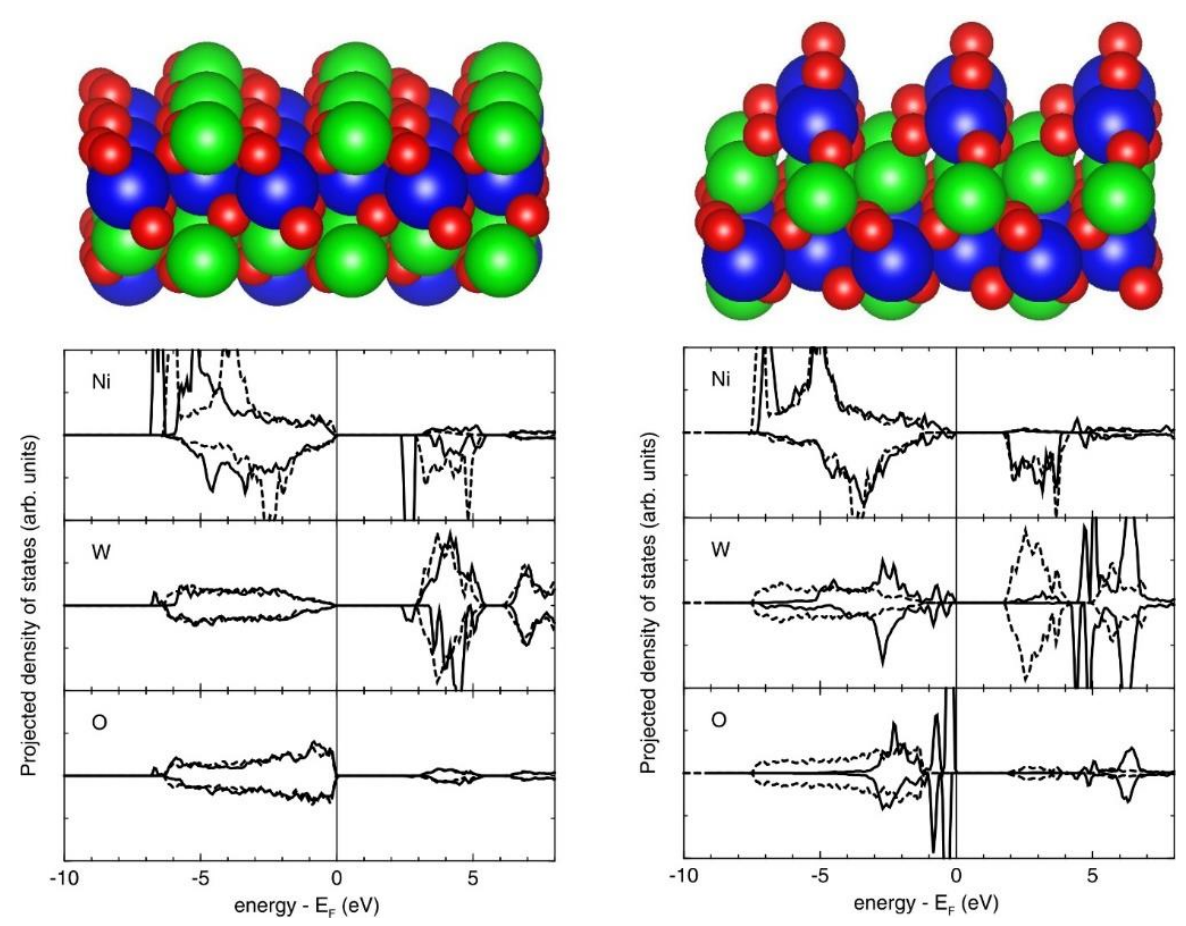

Figure 8. Top: side views of the $\mathrm{Ni}$ - terminated (left) and $\mathrm{W}=\mathrm{O}$ - terminated (right) $\mathrm{NiWO}_{4}(100)$ (1x1) surface. W, Ni and $\mathrm{O}$ atoms are represented in blue, green and red spheres, respectively. Only five top layers are shown in the upper panels and three in the lower panels. Bottom: their LDOS projected on surface atoms (solid lines) and central atoms (dashed lines).

Figure 8 (bottom part) displays the local density of states (LDOS) projected on surface atoms at the $\mathrm{Ni}$ (left panel) and $\mathrm{W}=\mathrm{O}$ (right panel) terminations together with the projection on the corresponding atoms in the slab center. On the Ni termination, the main feature is a strong $\mathrm{Ni}$ surface state at the bottom of the conduction band (CB), leading to a gap reduction of $0.6 \mathrm{eV}$. 
Due to its low coordination (three oxygen neighbors instead of six) and despite the contraction of the three remaining $\mathrm{Ni}-\mathrm{O}$ bonds, the surface $\mathrm{Ni}$ experiences a reduced electrostatic (Madelung) potential which lowers its unoccupied $d$ states into the bulk band gap. The top of the valence band (VB) has a strong oxygen character, with nevertheless a noticeable mixing with $\mathrm{Ni}$ states. These features of the electronic structure and the geometric position of the outermost $\mathrm{Ni}$ atoms above the surface oxygen layer produce a very well defined contrast in STM images, simulated under the Tersoff-Hamann approximation, especially at positive bias (Figure S2, Supplementary material).

On the $\mathrm{W}=\mathrm{O}$ termination, a high density of surface states exists at the top of the $\mathrm{VB}$, inducing a gap reduction of about $1.3 \mathrm{eV}$ (Fig. 8, right panel). These states are strongly localized on the singly-coordinated oxygen atom bound to the surface W. The LDOS displays a double peak, associated to the $p_{\mathrm{z}}$ oxygen orbital for the lowest energy peak and $p_{\mathrm{x}} / p_{\mathrm{y}}$ for the higher one. As expected from its geometric position above the surface and from the contribution of its orbitals to the top of the VB, the on-top oxygen atom gives strong simulated STM contrast, especially at negative bias (Figure S2, Supplementary material).

The surface configurations considered so far correspond to a chessboard arrangement of half a layer of surface cations and consequently produce a dense chessboard-like pattern in simulated STM images. Several alternative regular arrangements of surface cations can be conceived, respecting the polarity compensation criterion. In the following we focus on the row-wise arrangement of the surface cations. Following the experimental indications, we use a surface unit cell spanned by the diagonals of the NiWO $4(100)$ unit cell: $\vec{A}=\vec{b}+\vec{c}$ and $\vec{B}=$ $2 *(\vec{c}-\vec{b})(A=7.61 \AA, B=15.21 \AA)$, with the cationic rows oriented along the short axis $\vec{A}$ and every second row missing along the $\vec{B}$ axis (Figure S3, Supplementary material).

The Ni-terminated row-wise configuration (Fig. 9a) is only by $0.09 \mathrm{~J} / \mathrm{m}^{2}$ less stable than the chessboard one. It is characterized by a dimerization of the $\mathrm{Ni}$ atoms along the rows, with successive Ni-Ni distances equal to 3.24 and $4.53 \AA$. Interestingly, the simulated STM image (Fig. 9c) of this configuration displays a single elongated spot per dimer, located close to midway between the Ni-Ni atoms. Such STM signature of Ni dimers is reminiscent of the slightly elongated spots in the experimental images. At the $\mathrm{W}=\mathrm{O}$ termination (Fig. 9b) the row-wise and chessboard termination are nearly iso-energetic. At this termination, the dimerization does not alter the STM signature (Fig. 9d), with a separate spot for each on-top oxygen atom. 

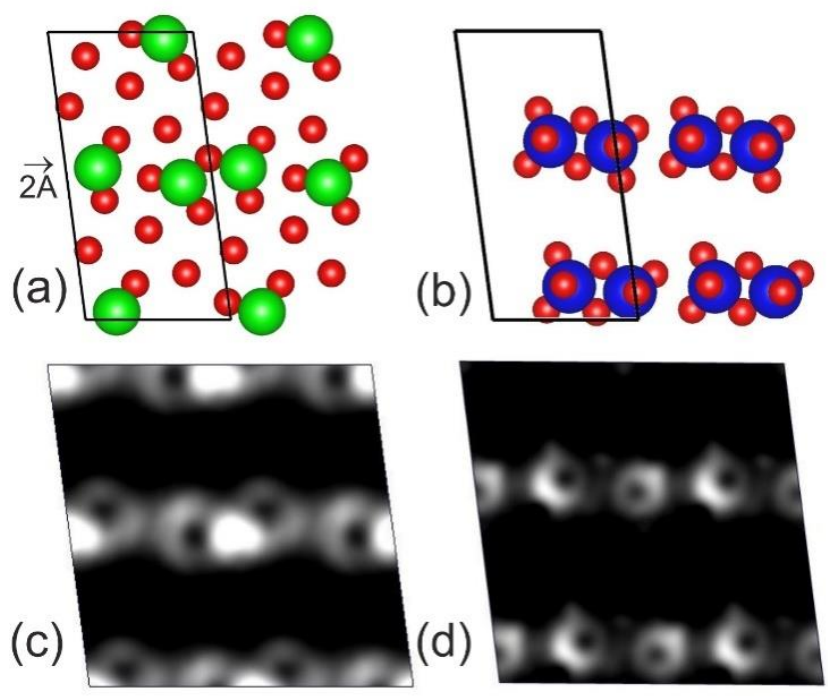

Figure 9. Top view of the outermost atoms of the $\mathrm{Ni}$ - terminated (a) and $\mathrm{W}=\mathrm{O}$ - terminated (b) reconstructed $\mathrm{NiWO}_{4}(100)$ surfaces. The simulated STM images of the models in (a) and (b), obtained at bias $-1 \mathrm{~V}$ and $3 \mathrm{~V}$ (with respect to the VB maximum), respectively are shown in (c) and (d). The unit cell is doubled along the $\vec{A}$ axis.

\section{DISCUSSION}

Our XPS and XRD results identify unambiguously the chemical composition and the crystalline structure of the nickel tungstate film on the $\mathrm{Ni}(110)$ surface as stoichiometric $\mathrm{NiWO}_{4}$ with the wolframite structure. According to the XRD scans and pole figures (Fig. 3) the $\mathrm{NiWO}_{4}$ film grows with its (100) and/or (100) crystal planes parallel to the $\mathrm{Ni}(110)$ substrate. Moreover, the $\mathrm{NiWO}_{4}$ film is rotationally aligned with the substrate to achieve best lattice matching, which is realized when the diagonals of the $\mathrm{NiWO}_{4}(100)$ unit cell (running in the $\mathrm{NiWO}_{4}<011>$ directions) are parallel to the Ni[110] direction. The STM images reveal a more complex picture of the morphology of the $\mathrm{NiWO}_{4}$ film, which grows initially as $3 \mathrm{D}$ crystallites exposing several facets, with the most dominant ones being the top facet $\mathrm{A}$ and a side facet $\mathrm{B}$. Upon increasing the coverage the $\mathrm{NiWO}_{4}$ crystallites coalesce and form a rough film which is terminated exclusively by the A - facets. Both the A - and B - facets display oblique unit cells, whose size and symmetry differ significantly from the rectangular unit cell of the $\mathrm{NiWO}_{4}(100)$ surface. Considering the small angle that they form with respect to the (100) orientation, they may be considered as vicinal to the (100) surface. 
To elucidate the effect of misorientation on the stability of the (100) surface, we have considered a series of vicinal terminations, with (100) terraces separated by steps running along $\mathrm{NiWO}_{4}<011>$ direction. Since such steps require (n11) step ledges, we have chosen the (211) ones due to their low surface energy (Table 1). Construction of such vicinal surfaces, with different proportions of polar (100) terraces and non-polar (211) ledges, rises a general question of polarity compensation condition at facetted surfaces. Indeed, the standard evaluation of compensating charge density from the dipole density of the repeat unit cell is possible, but becomes cumbersome in such complex case. A method in which the polarity of ledges and terraces is separately compensated raises the question of how to treat edge and counter-edge atoms. The safer method, when possible, consists in representing the vicinal surfaces by stoichiometric symmetric slabs. Since, in such case, a stoichiometric bulk repeat unit without dipole moment can always be found ${ }^{53}$ and since both the bulk region and each surface region are stoichiometric, the two surfaces are necessarily charge-neutral and thus polar compensated.

Table 2 summarizes results on the series of surfaces with an increasing proportion of (211) ledges. They all display surface energies smaller than the planar (100) one. The energy reduction is driven by the contribution of the (211) ledges, whose energy is lower than that of (100) terraces. As a consequence, surface energies strongly decrease as the proportion of (211) facets increases, thus pointing towards a thermodynamic preference for a strong faceting of the (100) surface. These results suggest that the limited faceting found in the experiment is likely due to the thinness of the $\mathrm{NiWO}_{4}$ film and to its non-negligible interaction with the Ni substrate.

\begin{tabular}{|c|c|c|c|c|c|}
\hline Surface & $\begin{array}{c}\text { Es } \\
\left(\mathrm{J} / \mathrm{m}^{2}\right)\end{array}$ & $\begin{array}{c}\mathrm{A} \\
(\AA)\end{array}$ & $\begin{array}{c}\mathrm{B} \\
(\AA)\end{array}$ & $\begin{array}{c}\theta \\
\left({ }^{\circ}\right)\end{array}$ & $\begin{array}{c}\Psi \\
\left({ }^{\circ}\right)\end{array}$ \\
\hline$(100)$ & 1.01 & 7.61 & 5.02 & 90.0 & 0 \\
\hline$(8 \underline{1})$ & 0.96 & 7.61 & 15.91 & 97.2 & 16 \\
\hline$(4 \underline{1})$ & 0.91 & 7.61 & 8.92 & 96.4 & 30 \\
\hline$(3 \underline{1} 1)$ & 0.80 & 7.61 & 15.57 & 110.0 & 40 \\
\hline$(2 \underline{1} 1)$ & 0.77 & 7.61 & 6.84 & 118.9 & 43 \\
\hline
\end{tabular}


Table 2. Structural and energetic characteristics of a series of surfaces vicinal to the (100) one with an increasing proportion of (211) ledges: surface energy $\mathrm{E}_{\mathrm{s}}$; lengths (A and B) and angle $\theta$ between their 2D lattice vectors; their misorientation angle $\psi$ with respect to (100) surface.

We note that all structural characteristics of the (811) surface (the lengths of its lattice parameters $\mathrm{A}$ and $\mathrm{B}$, the angle $\theta$ between them, and its misorientation angle $\psi$ with respect to the (100) surface) match very closely the experimental structure of the A facet. The B facet corresponds most likely to a (1611) vicinal orientation: $\mathrm{A}=7.61 \AA, \mathrm{B}=30.78 \AA$, $\theta=97.5^{\circ}, \psi=8.7^{\circ}$. This surface has not been explicitly included in the present series of ab initio calculations, but from Table 2 its energy can be estimated in the range $0.96-1.0 \mathrm{~J} / \mathrm{m}^{2}$.

Figure 10 shows two models of the vicinal (811) surface in which one recognizes a small (211) ledge facet (Figure S1 in Supplementary material). Model I (Fig. 10a) has a Ni-type step edge and two additional $\mathrm{Ni}$ atoms on the (100) terrace in a row-wise configuration per unit cell. The corresponding surface energy is equal to $1.09 \mathrm{~J} / \mathrm{m}^{2}$. More stabilization can be obtained by removing one $\mathrm{NiWO}_{4}$ formula unit from each step edge (Model II - Fig. 10b), $\mathrm{E}_{\mathrm{s}}$ $=0.96 \mathrm{~J} / \mathrm{m}^{2}$. In this case a $\mathrm{W}=\mathrm{O}$-type edge is obtained, with an oxygen atom in an on-top position and a short $\mathrm{W}=\mathrm{O}$ bond characteristic of an oxo-ligand. It is worthwhile noting that the row-wise arrangement of $\mathrm{Ni}$ atoms on the terraces is slightly more stable than the chessboard one, at variance with the result on the planar (100) surface.

(a)

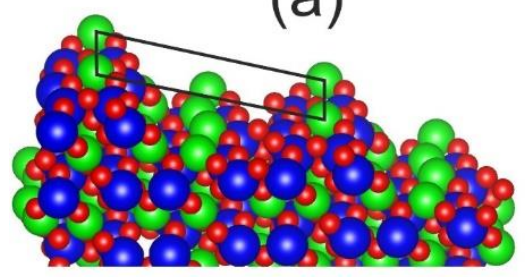

(c)

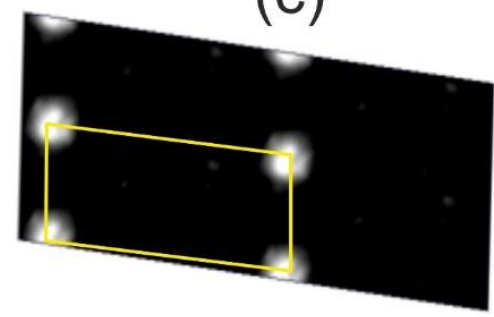

(b)

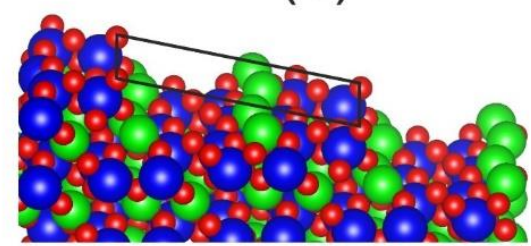

(d)

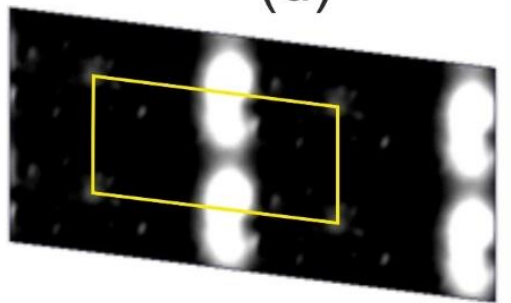

Figure 10. Two proposed models (side views perpendicular to the $\vec{A}$ vector of the structure) of the $\mathrm{NiWO}_{4}(8 \underline{11})$ vicinal surface. $\mathrm{Ni}$ atoms on the terraces are arranged in a row-wise configuration and the step edge is Ni-terminated (a) or W=O terminated (b). The simulated STM images of (a) and (b) obtained at bias $3 \mathrm{~V}$ (with respect to the VB maximum) are shown in Fig. 10 (c) and (d), respectively. 
The $\mathrm{NiWO}_{4}$ (811) unit cell is indicated on the structure models (black line) and the STM images (yellow line).

For these two vicinal surfaces, we have simulated STM images (Figs. 10c and 10d). On the $\mathrm{Ni}$-edge termination, the bright spots correspond to $\mathrm{Ni}$ atoms on the step edges, which are both at the highest position and display a high density of states in the energy window upon consideration. $\mathrm{Ni}$ atoms located on the terraces are almost invisible, due to their lower position. On the $\mathrm{W}=\mathrm{O}$ edge termination, the bright elongated spots in the STM simulated image (Fig. 10d) correspond to the $\mathrm{Ni}$ on the terraces, and the very weak central spots to states localized on the $\mathrm{W}=\mathrm{O}$ moiety and thus reproduces very well the contrast of the experimental STM image of the (811) facets (Fig. 7a).

\section{CONCLUSIONS}

The growth and surface structure of ultrathin $\mathrm{NiWO}_{4}$ films on a $\mathrm{Ni}(110)$ surface was studied for the first time experimentally using XPS, XRD and STM and analyzed theoretically by DFT calculations. It is shown that the $\mathrm{NiWO}_{4}$ film grows epitaxially with the (100) planes of the wolframite structure parallel to the $\mathrm{Ni}(110)$ surface and is rotationally aligned to the substrate, such that the $\mathrm{NiWO}_{4}[011]$ direction is parallel to the $\mathrm{Ni}[110]$ direction. The oxide film shows a complex surface morphology displaying mainly two crystalline facets corresponding to (1611) and (811) planes, which are vicinal to the $\mathrm{NiWO}_{4}(100)$ surface. Several mechanisms for the stabilization of the polar $\mathrm{NiWO}_{4}(100)$ surface have been investigated in the DFT calculations, including chessboard and row-wise reconstructions of the (100) plane, as well as more complex faceting into high-index stepped surfaces. It is found that the latter mechanism leads to a more substantial lowering of the surface energy thanks to the presence of low energy (211) ledges. Inspired by the experimental STM results, a theoretical model has been proposed for the (811) vicinal surface, which consists of (100) terraces with outermost $\mathrm{Ni}$ dimers, (211) ledges, and $\mathrm{W}=\mathrm{O}$ groups on the step edges. It is concluded that the observed stabilization of the vicinal facets is the result of a competition between the reduction of surface energy, the interface lattice matching with the $\mathrm{Ni}(110)$ substrate, and the confinement effects in the ultrathin $\mathrm{NiWO}_{4}$ film. In the context of various applications for which surface and its reactivity are important, our study shows the possibility 
of stabilizing nanoparticles with high-energy facets (thus with lower-coordinated and more reactive surface sites).

\section{ASSOCIATED CONTENT}

\section{Supporting Information}

Structure of different $\mathrm{NiWO}_{4}$ low energy surfaces (Figure S1); Structural and electronic characteristics of various $\mathrm{NiWO}_{4}(100)$ (1x1) surface terminations (Table S1); Simulated STM images of the Ni- and $\mathrm{W}$-terminated $\mathrm{NiWO}_{4}(100)-(1 \times 1)$ surfaces (Figure $\mathrm{S} 2$ ); Top view of the bulk-truncated (100) surface with the indication of the (1x1) unit cell and the rotated cell with $\vec{A}=\vec{b}+\vec{c}$ and $\vec{B}=2 *(\vec{c}-\vec{b})$ axis (Figure S3).

\section{AUTHOR INFORMATION}

\section{Corresponding authors:}

svetlozar.surnev@uni-graz.at

jacek.goniakowski@insp.jussieu.fr

\section{Notes}

The authors declare no competing financial interest.

\section{ACKNOWLEDGEMENTS}

This work has been supported by the FWF Project P26633-N20 and the EU COST Action CM 1104. The technical support of the Elettra staff at the synchrotron in Trieste, Italy, is gratefully acknowledged. 


\section{REFERENCES}

(1) Gil-Llambias, F. J.; Rodriguez, H.; Bouyssiers, I.; Escudey, M.; Carkovic, I. Hydrodesulfurization Catalysts: Electrophoretic Study of Mo (or W)-Co, Mo (or W)Ni, and Mo (or W)-Ca Sulfided Phases. J. Catal. 1986, 102, 37-42.

(2) Scheffer, B.; Molhoek, P.; Moulijn, J. A. Temperature-Programmed Reduction of $\mathrm{NiO}-\mathrm{WO}_{3} / \mathrm{A}_{2} \mathrm{O}_{3}$ Hydrodesulphurization Catalysts. Appl. Catal. 1989, 46, 11-30.

(3) Diaz-Real, R. A.; Mann, R. S.; Sambi, I. S. Hydrotreatment of Athabasca Bitumen Derived Gas Oil over Nickel-Molybdenum, Nickel-Tungsten, and CobaltMolybdenum Catalysts. Ind. Eng. Chem. Res. 1993, 32,1354-1358.

(4) Stern, D. L.; Grasselli, R. K. Propane Oxydehydrogenation over Metal Tungstates. J. Catal. 1997, 167, 570-572.

(5) Bi, Y.; Nie, H.; Li, D.; Zeng, S.; Yang, Q.; Li, M. NiWO 4 Nanoparticles: A Promising Catalyst for Hydrodesulfurization. Chem. Commun. 2010, 46, 7430-7432.

(6) Pourmortazavi, S. M.; Rahimi-Nasrabadi, M.; Khalilian-Shalamzari, M.; Zahedi, M. M.; Hajimirsadeghi, S. S.; Omrani, I. Synthesis, Structure Characterization and Catalytic Activity of Nickel Tungstate Nanoparticles. Appl. Surf. Sci. 2012, 263, 745752.

(7) Mohamed, M. M.; Ahmed, S. A.; Khairou, K. S. Unprecedented High Photocatalytic Activity of Nanocrystalline $\mathrm{WO}_{3} / \mathrm{NiWO}_{4}$ Hetero-junction towards Dye Degradation: Effect of Template and Synthesis Conditions. Appl. Catal. B: Env. 2014, 150, 63-73.

(8) Bhattacharya, A. K.; Biswas, R. G.; Hartridge, A. Environment Sensitive Impedance Spectroscopy and DC Conductivity Measurements on $\mathrm{NiWO}_{4}$. J. Mater. Sci. 1997, 32, 353-353.

(9) Dusastre, V.; Williams, D. E. Symmetrical Alkyl-substituted Oligothiophenes as Ligands: Complexation of the $\left[\left(\eta-\mathrm{C}_{5} \mathrm{H}_{5}\right) \mathrm{Ru}\right]^{+}$Moiety by Hexyl-substituted Ter-, Quater- and Quinque-thiophenes. J. Mater. Chem. 1999, 9, 865-874.

(10) Sundaram, R.; Nagaraja, K. S. Electrical and Humidity Sensing Properties of Lead(II) Tungstate-Tungsten(VI) Oxide and Zinc(II) Tungstate-Tungsten(VI) Oxide Composites. Mater. Res. Bull. 2004, 39, 581-590.

(11) Pullar, R. C.; Farrah, S.; Alford, N. Mc N. $\mathrm{MgWO}_{4}, \mathrm{ZnWO}_{4}, \mathrm{NiWO}_{4}$ and $\mathrm{CoWO}_{4}$ Microwave Dielectric Ceramics. J. Eur. Ceram. Soc. 2007, 27, 1059-1063.

(12) Pandey, R. S.; Bhave, N. S.; Kharat, R. B. Structural, Optical, Electrical and Photovoltaic Electrochemical Characterization of Spray Deposited $\mathrm{NiWO}_{4}$ Thin Films. Electrochim. Acta 2006, 51, 4659-4664. 
(13) Zhu, J.; Li, W.; Li, J.; Li, Y.; Hu, H.; Yang, Y. Photoelectrochemical Activity of $\mathrm{NiWO}_{4} / \mathrm{WO}_{3}$ Heterojunction Photoanode under Visible Light Irradiation. Electrochim. Acta 2013, 112, 191-198.

(14) Kuzmin, A.; Purans, J.; Kalendarev, R.; Pailharey, D.; Mathey, Y. XAS, XRD, AFM and Raman Studies of Nickel Tungstate Electrochromic Thin Films. Electrochim. Acta 2001, 46, 2233-2236.

(15) Green, S. V.; Pehlivan, E.; Granqvist C. G.; Niklasson, G. A. Electrochromism in Sputter Deposited Nickel-containing Tungsten Oxide Films. Sol. Energy Mater. Sol. Cells 2012, 99, 339-344.

(16) Green, S. V.; Granqvist C. G.; Niklasson, G. A. Structure and Optical Properties of Electrochromic Tungsten-containing Nickel Oxide Films. Sol. Energy Mater. Sol. Cells 2014, 126, 248-259.

(17) Keeling Jr., R. O. Structure of NiWO4. Acta Cristallogr. 1957, 10, 209-213.

(18) Weitzel, H. Kristallstrukturverfeinerung von Wolframiten. Z. Kristallogr. 1976, 144, 238-258.

(19) Oishi, S.; Furuichi, Y.; Kitajima, K. Growth of $\mathrm{NiWO}_{4}$ Crystals from a $\mathrm{Na}_{2} \mathrm{~W}_{2} \mathrm{O}_{7}$ Flux. J. Mater. Sci. 1996, 31, 5309-5312 and references therein.

(20) Netzer, F.P.; Surnev, S. Ordered Oxide Nanostructures on Metal Surfaces, Oxide Ultrathin Films, 2012, Wiley-VCH Verlag GmbH \& Co. KGaA, Eds. G. Pacchioni and S. Valeri.

(21) Denk, M.; Kuhness, D.; Wagner, M.; Surnev, S.; Negreiros, F.R.; Sementa, L.; Barcaro, G.; Vobornik, I.; Fortunelli, A.; Netzer, F.P. Metal Tungstates at the Ultimate Two-Dimensional Limit: Fabrication of a $\mathrm{CuWO}_{4}$ Nanophase. ACS Nano 2014, 8, 3947-3954.

(22) Pomp, S.; Kuhness, D.; Barcaro, G.; Sementa, L.; Mankad, V.; Fortunelli, A.; Sterrer, M.; Netzer, F. P.; Surnev, S. Two-dimensional Iron Tungstate: a Ternary Oxide Layer with Honeycomb Geometry. J. Phys. Chem. C 2016, 120, 7629-7638.

(23) Steurer, W.; Allegretti, F.; Surnev, S.; Barcaro, G.; Sementa, L.; Negreiros, F.; Fortunelli, A.; Netzer, F. P. Metamorphosis of Ultrathin Ni-oxide Nanostructures on Ag(100), Phys. Rev. B 2011, 84, 115446.

(24) FitXPS Version 2.12, D.L. Adams, Univ. of Aarhus, Denmark. 
(25) Doniach, S.; Šunjić, M. Many-electron Singularity in X-ray Photoemission and X-ray Line Spectra from Metals, J. Phys. C 1970, 3, 285-291.

(26) Swanson, H. E. Standard X-ray Diffraction Powder Patterns. Nat. Bur. Stand. Cir. 1953, 1

(27) Cairns, R. W.; Ott, E. X-Ray Studies of the System Nickel-Oxygen-Water. I. Nickelous Oxide and Hydroxide. J. Am. Chem. Soc. 1933, 55, 527-533.

(28) Kraus, W.; Nolze, G. POWDER CELL - A Program for the Representation and Manipulation of Crystal Structures and Calculation of the Resulting X-ray Powder Patterns. J. Appl. Crystallogr. 1996, 29, 301-303.

(29) Shultz, L. G. A Direct Method of Determining Preferred Orientation of a Flat Reflection Sample Using a Geiger Counter X-Ray Spectrometer J. Appl. Phys. 20 (1949) 1030-1032.

(30) Salzmann, I.; Resel, R. STEREOPOLE: Software for the Analysis of X-ray Diffraction Pole Figures with IDL. J. Appl. Crystallogr. 2004, 37, 1029-1033.

(31) Eierdal, L.; Besenbacher, F.; Lægsgaard, E.; Stensgaard, I. Interaction of Oxygen with Ni(110) Studied by Scanning Tunneling Microscopy. Surf. Sci. 1994, 312, 31-53.

(32) Kresse, G.; Hafner, J. Ab initio Molecular-Dynamics Simulation of the Liquid-MetalAmorphous-Semiconductor Transition in Germanium. Phys. Rev. B 1994, 49, 14251; Kresse, G.; Furthmüller, J. Efficient Iterative Schemes for Ab initio Total-energy Calculations using a Plane-wave Basis Set. Phys. Rev. B 1996, 54, 11169.

(33) Blöchl, P. E. Projector Augmented-wave Method. Phys. Rev. B 1994, 50), 17953; Kresse, G.; Joubert, D. From Ultrasoft Pseudopotentials to the Projector Augmentedwave Method. Phys. Rev. B 1999, 59, 1758.

(34) Perdew, J. P.: Chevary, J. A.; Vosko, S. H.; Jackson, K. A.; Pederson, M. R.; Singh D. J.; Fiolhais, C. Atoms, Molecules, Solids, and Surfaces: Applications of the Generalized Gradient Approximation for Exchange and Correlation. Phys. Rev. B 1992, 46, 6671 .

(35) Dudarev, S. L.; Botton, G. A.; Savrasov, S. Y.; Humphreys, C. J.; Sutton, A. P. Electron-Energy-Loss Spectra and the Structural Stability of Nickel Oxide: An LSDA+U Study. Phys. Rev. B 1998, 57, 1505.

(36) Kuzmin, A.; Kalinko, A.; Evarestov, R. A. First-principles LCAO Study of Phonons in $\mathrm{NiWO}_{4}$. Cent. Eur. J. Phys. 2011, 9, 502-509. 
(37) Ejima, T.; Banse, T.; Takatsuka, H.; Kondo, Y.; Ishino, M.; Kimura, N.; Watanabe, M.; Matsubara, I. Microscopic Optical and Photoelectron Measurements of $\mathrm{MWO}_{4}$ (M=Mn, Fe, and Ni). J. Lumin. 2006, 119-120, 59-63.

(38) Noguera, C. Physics and Chemistry at Oxide Surfaces, Cambridge University Press, Cambridge, 1996

(39) Nilius, N.; Fedderwitz, H.; Groß, B.; Noguera C.; Goniakowski, J. Incorrect DFTGGA Predictions of the Stability of Non-stoichiometric/Polar Dielectric Surfaces: the Case of $\mathrm{Cu}_{2} \mathrm{O}(111)$. Phys. Chem. Chem. Phys. 2016, 18, 6729-6733.

(40) Momma, K.; Izumi, F. VESTA 3 for Three-dimensional Visualization of Crystal, Volumetric and Morphology Data. J. Appl. Crystallogr. 2011, 41, 1272-1276.

(41) Hüfner, S. Photoelectron spectroscopy, Solid State Science Series, 1995 vol. 82 (Springer-Verlag).

(42) van Veenendaal, M. A.; Sawatzky, G. A. Nonlocal Screening Effects in 2p X-ray Photoemission Spectroscopy Core-level Line Shapes of Transition Metal Compounds. Phys. Rev. Lett. 1993, 70, 2459.

(43) Alders, D.; Voogt, F. C.; Hibma, T.; Sawatzky, G. A. Nonlocal Screening Effects in 2p X-ray Photoemission Spectroscopy of NiO (100). Phys. Rev. B 1996, 54, 7716.

(44) Preda, I.; Gutiérrez, A.; Abbate, M.; Yubero, F.; Méndez, J.; Alvarez, L.; Soriano, L. Interface Effects in the Ni $2 p$ X-ray Photoelectron Spectra of NiO Thin Films Grown on Oxide Substrates. Phys. Rev. B 2008, 77, 075411.

(45) Powell, C. J.: Jablonski, A. NIST Electron Inelastic-Mean-Free-Path Database, 2010, Version 1.2.

(46) Kuhlenbeck, H.; Odörfer, G.; Jaeger, R.; Illing, G.; Menges, M.; Mull, Th.; Freund, H.-J.; Pöhlchen, M.; Staemmler, V.; Witzel, S.; Scharfschwerdt, C.; Wennemann, K.; Liedtke, T.; Neumann, M. Molecular Adsorption on Oxide Surfaces: Electronic Structure and Orientation of $\mathrm{NO}$ on $\mathrm{NiO}(100) / \mathrm{Ni}(100)$ and on $\mathrm{NiO}(100)$ as Determined from Spectroscopies and Ab initio Cluster Calculations. Phys. Rev. B 1991, 43, 1969.

(47) Caffio, M.; Cortigiani, B.; Rovida, G.; Atrei A.; Giovanardi, C. Early Stages of NiO Growth on $\operatorname{Ag}(001)$ : A Study by LEIS, XPS, and LEED. J. Phys. Chem. B 2004, 108, 9919-9926.

(48) Wulser, K. W.; Hearty, B. P.; Langell, M. A. NiO(100) Valence-band Density of States During Hydrogen Reduction. Phys. Rev. B 1992, 46, 9724. 
(49) Agnoli, S.; Barolo, A.; Finetti, P.; Sedona, F.; Sambi, M.; Granozzi, G. Core and Valence Band Photoemission Study of Highly Strained Ultrathin NiO Films on Pd(100). J. Phys. Chem. C 2007, 111, 3736-3743.

(50) Mancheva, M. N.; Iordanova, R. S.; Klissurski, D. G.; Tyuliev, G. T.; Kunev, B. N. Direct Mechanochemical Synthesis of Nanocrystalline $\mathrm{NiWO}_{4}$. J. Phys. Chem. C 2007, 111, 1101-1104.

(51) Green, S. V.; Kuzmin, A.; Purans, J.; Granqvist, C. G.; Niklasson, G. A. Structure and Composition of Sputter-deposited Nickel-Tungsten Oxide Films. Thin Solid Films 2011, 519, 2062-2066.

(52) Tasker, P.W. The Stability of Ionic Crystal Surfaces. J. Phys. C: Solid State Phys. 1979, 12, 4977-4984.

(53) Goniakowski, J.; Finocchi, F.; Noguera, C. Polarity of Oxide Surfaces and Nanostructures. Rep. Prog. Phys. 2008, 71, 016501.

(54) Noguera, C.; Goniakowski, J. Polarity in Oxide Nano-objects. Chem. Rev. 2013, 113, 4073-4105.

(55) Nugent, W. A.; Mayer, J. M. Metal-ligand multiple bonds. 1988, John Wiley \& Sons, New York.

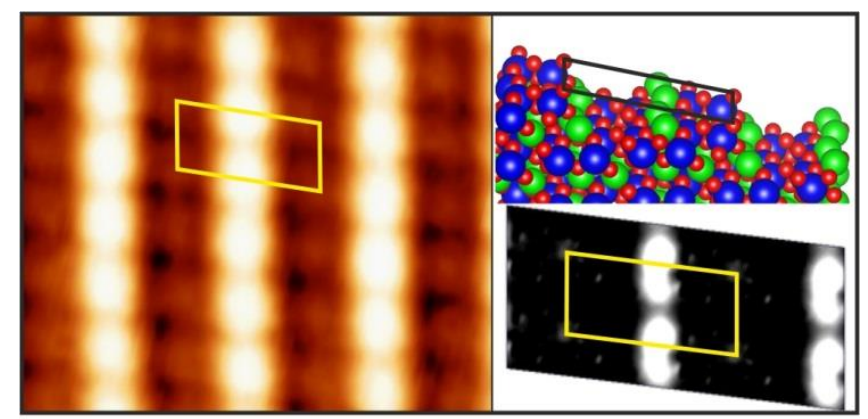

TOC Graphic 